\title{
Stress corrosion behavior of X80 pipeline steel in the natural seawater with different dissolved oxygen contents
}

\author{
Zhong-ying Han \\ School of Petroleum Engineering, China University of Petroleum (East China), Qingdao, 266580, China. \\ banzbying@upc.edu.cn \\ Xiao-guang Huang \\ College of Pipeline and Civil Engineering, China University of Petroleum (East China), Qingdao, 266580, China. \\ buangxg@upc.edu.cn
}

\begin{abstract}
Stress corrosion slow strain rate tensile tests of the X80 steel in the natural seawater are carried out to study the effect of dissolved oxygen (DO) on the sensitivity of stress corrosion. Scanning electron microscope (SEM) combined with the electrochemical measurement is adopted to analyze the mechanism and affecting factor of the stress corrosion cracking (SCC). The results show that the sensitivity of SCC in the natural seawater increases and the stress corrosion cracking gradually transforms from ductile to quasibrittle fracture, with the increase of dissolved oxygen content. Tafle polarization curves and electrochemical impedance spectroscopy of X80 steel show that the dissolved oxygen aggravates the electrochemical corrosion and reduces the corrosion resistance. The corrosion pits and micro cracks at the lateral and fracture surface trigger the stress concentration and promote the anodic dissolution under the applied stress, thereby accelerate the process of stress corrosion cracking of the X80 steel.
\end{abstract}

KEYWORDS. Stress corrosion; Dissolved oxygen; Sensitivity; Stress concentration; Anodic dissolution.

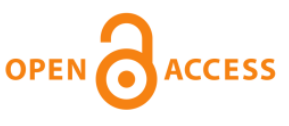

Citation: Han, Z. Y., Huang, X. G., Stress corrosion behavior of $\mathrm{X} 80$ pipeline steel in natural seawater with different dissolved oxygen, Frattura ed Integrità Strutturale, 50 (2019) 20-28.

Received: 11.04.2018

Accepted: 07.07.2019

Published: 01.10.2019

Copyright: (C) 2019 This is an open access article under the terms of the CC-BY 4.0, which permits unrestricted use, distribution, and reproduction in any medium, provided the original author and source are credited.

\section{INTRODUCTION}

$\mathrm{S}$ ubmarine pipeline is an indispensable part and the lifeline of offshore oil-gas exploitation. During the laying and service period, submarine pipelines are often subjected to various loadings, such as the internal pressure, temperature, bending, and wave and flow [1-2]. Under the interaction of these external loadings, the inner and outer coatings of pipeline are easy to break or fall off. Once the seawater penetrates, the corrosion of pipeline is inevitable. The coupling effect of corrosion and stress is easy to induce the stress corrosion failure even under very lower stress and this greatly shortens the service life of the pipeline [3-4]. Rupture of the pipeline and the accompanying oil leakage often result in a 
serious environmental pollution and huge economic losses. Therefore, stress corrosion failure has aroused a worthy concern for safe service of the submarine pipeline [5-6].

Stress corrosion cracking (SCC) is a low-stress brittle cracking phenomenon of pipeline steel under the coupling of stress and a specific corrosive environment. Unlike corrosion fatigue, stress corrosion has an obvious dependence on material and environment. SCC occurs in an environment that contains corrosive media such as $\mathrm{CO}_{2}, \mathrm{H}_{2} \mathrm{~S}, \mathrm{Cl}, \mathrm{OH}, \mathrm{HCO}_{3}^{-}$, and $\mathrm{CO}_{3}^{2-}$ [7]. According to the $\mathrm{pH}$ value of the service environment, SCC of the pipelines steel can be divided into high, near neutral and low $\mathrm{pH}$ types. At present, the research on the SCC of the pipeline steel mainly focuses on the near neutral and high-pH SCC. The high-pH SCC mainly occurs in the soil environment ( $\mathrm{pH} 8 \sim 10.5)$ with high concentration of $\mathrm{Na}_{2} \mathrm{CO}_{3}$ and $\mathrm{NaHCO}_{3}$ and induces an intergranular cracking [8]. The mechanism of the high-pH SCC is consistently recognized to be the film rupture and slip dissolution [9-10]. However, the transgranular SCC often occurs in the near neutral (pH 6 8) environment. At present, the stress corrosion mechanism of pipeline steel in a near neutral environment has been widely accepted as the interaction of anodic dissolution and hydrogen embrittlement. However, in a marine environment, the situation may be more serious. For example, high concentration of $\mathrm{Cl}^{-}$accelerates the pitting corrosion and greatly promote the crack nucleation of SCC [11]. Additionally, the subsea is a complex and changeable corrosive environment with various hydrostatic pressures, varying DO contents and $\mathrm{pH}$ values at different depths [12]. A number of studies have been performed to investigate the corrosion behavior of pipeline steel in the natural marine environment [13-15]. However, research work on the stress corrosion behavior of X80 pipeline steel in the natural seawater is very limited.

In this paper, the slow strain rate tensile (SSRT) tests of X80 steel were conducted to study the sensitivity of stress corrosion cracking in the natural seawater with different DO contents. SEM analyses of the lateral and fracture surface were complemented to investigate the mechanism of stress corrosion in different environments. Electrochemical polarization and impedance spectroscopy of the stressed X80 samples in the seawater were measured to explain the effect of DO on the corrosion and stress corrosion behavior. Also, a model that stress concentration promotes the anodic dissolution and the SCC fracture is adopted to explain this accelerating effect once the corrosion pits and microcracks are formed.

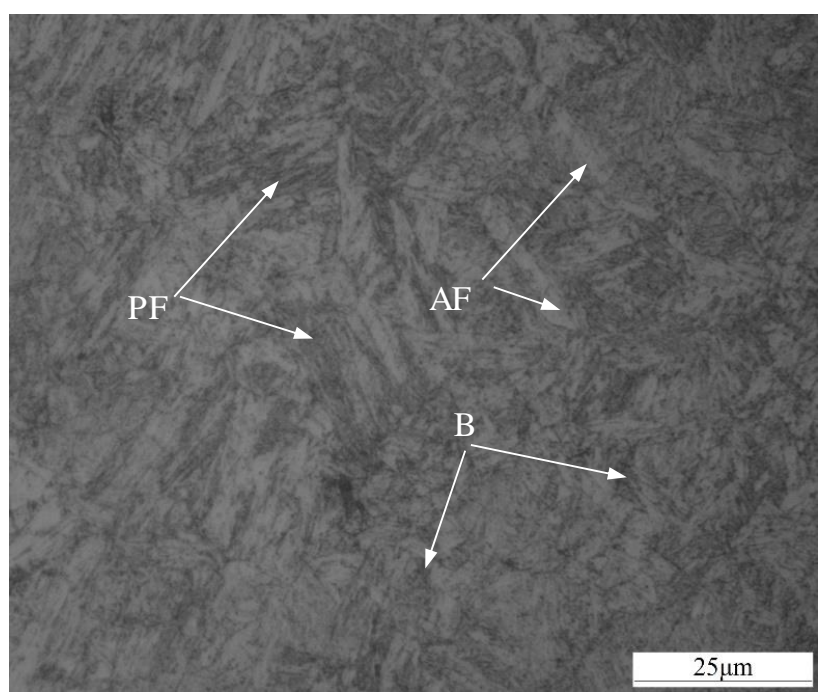

Figure 1: Microstructure of X80 steel.

\section{EXPERIMENTAL PROCESS}

\section{Samples}

he selected X80 pipeline steel for stress corrosion SSRT tests contains (w.t. \%) 0.055 C, $1.392 \mathrm{Mn}, 0.328$ Mo, 0.202 $\mathrm{Si}, 0.264 \mathrm{Ni}, 0.0017 \mathrm{P}, 0.002 \mathrm{~S}, 0.032 \mathrm{Cr}, 0.017 \mathrm{Al}$, and Fe rem. The microstructure of X80 pipeline steel is shown in Fig. 1. The microstructure is composed of acicular ferrite (AF), polygonal ferrite (PF), bainite (B), and many small precipitates dispersed in the matrix. The tested yield strength $\sigma_{\mathrm{s}}$ and tensile strength $\sigma_{\mathrm{b}}$ of $\mathrm{X} 80$ steel are $680 \mathrm{MPa}$ and $710 \mathrm{MPa}$, respectively, which indicated that the X80 steel has a better ability to resist deformation. The plate-shaped specimen shown in Fig. 2 is machined from an X80 steel plate by wire-cutting and fine grinding to achieve the requirement of accuracy. According to the literature [11], the DO content in seawater of China Sea varies from 2.6 to $6.8 \mathrm{mg} / \mathrm{L}$, gradually decreasing from $6.8 \%$ at shallow sea to $2.6 \%$ along with the depth of the seawater. To analyze the effect of DO on the stress corrosion 
behavior, the DO content of the natural seawater (DO: $6.8 \mathrm{mg} / \mathrm{L}$ ) is regulated to 2.6 , and $4.7 \mathrm{mg} / \mathrm{L}$ respectively by infilling with the high purity nitrogen $(99.9 \%)$, and the amount of nitrogen for each DO is obtained through the pre-test monitored by a JPB-607 dissolved oxygen meter.

\section{Experimental preparation}

The SSRT tests were run on a HLFS-50 slow strain rate tensile test system at a strain rate of $1 \times 10^{-6} \mathrm{~s}^{-1}$. During the SSRT tests, the system automatically recorded the stress-displacement curves, as well as the fractured lives of the samples. Each test was reproduced at least three times to ensure the reliability of the experimental data. The SCC sensitivity of the sample was evaluated by the elongation-loss rate $\left(I_{\delta}\right)$ and the reduction-in-area loss rate $\left(I_{\psi}\right)$. The definitions of these two parameters are:

$$
\begin{aligned}
& I_{\delta}=\left(1-\delta_{\mathrm{s}} / \delta_{0}\right) \times 100 \% \\
& I_{\psi}=\left(1-\psi_{\mathrm{s}} / \psi_{0}\right) \times 100 \%
\end{aligned}
$$

where $\delta_{\mathrm{s}}$ and $\psi_{\mathrm{s}}, \delta_{0}$ and $\psi_{0}$ are the elongation and reduction-in-area in air and in the seawater, respectively.

After the SSRT tests, the fracture surfaces of the specimens were cleaned by the distilled water and ethanol, respectively. A scanning electron microscope (SEM) was used to analyze the stress corrosion mechanism of the X80 steel in the seawater with different DO contents.

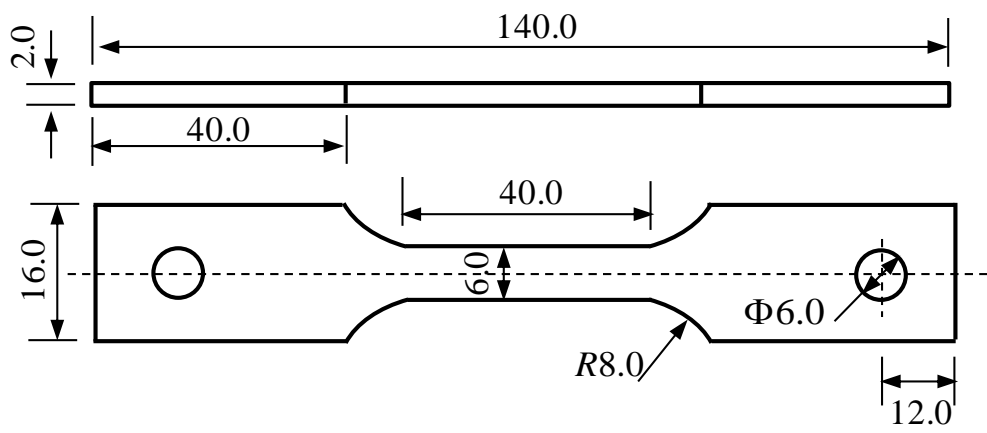

Figure 2: Dimensions of the SSRT test specimen (unit: $\mathrm{mm}$ ).

\section{EXPERIMENTAL RESULTS}

\section{Results of SSRT}

7 he stress-strain curves of the X80 specimens measured in the seawater with different DO contents are shown in Fig. 3 , and the stress-strain curve in air is also depicted for comparison. The tensile strength and elongation of X80 steel in seawater are obviously lower than that in air, and this decline increase with the increasing DO, indicating that X80 steel has a strong susceptibility of SCC to the DO in the seawater. The time-to-fracture of X80 steel in different environments can be obtained by the SSRT tests, as shown in Fig. 4. The stress corrosion lives decrease with the increase of DO, i.e., the stress corrosion of X80 steel is more serious in the shallow sea. Additionally, to investigate the sensitivity of SCC in the seawaters, two sensitivity factors of X80 steel, $I_{\delta}$ and $I_{\psi}$, in different environments are also shown in Fig. 5. As the DO increases, both $I_{\delta}$ and $I_{\psi}$ decrease at different extents, when compared with $42.1 \% I_{\delta}$ and $31.4 \% I_{\psi}$ measured in air.

\section{Fracture morphologies of SSRT tests}

Fig. 6 demonstrates the SEM images of the fractured surfaces after the SSRT tests in the seawater with different DO contents. The macro fracture morphology of X80 steel shows an apparent necking deformation when tested in air. While in the seawater, the necking deformation weakens with the increase of DO. The fracture surface in air exhibits many ductile dimples, showing a good ductile fracture property. While in the seawater, the appearances are completely different. The 
fracture region of X80 steel possesses some quasi-cleavage zones when testing in the $2.6 \%$ DO seawater, and there are still some small ductile dimples next to most quasi-cleavage of the fracture surface, as shown in Fig. 6(b). But the number of ductile dimples decreases and the size of ductile dimples also shrinks when DO increases to $6.8 \%$, and the fracture surface is primarily composed of quasi-cleavage which is seen as the main characteristic of transgranular fracture, as shown in Fig. 6(d). It indicates that the fracture in the seawater gradually transforms from ductile fracture to brittle one with the increase of DO content. At the same time, a large number of stripes in river patterns appear at the fracture surface, showing the increase of SCC susceptibility with the increase of DO content.

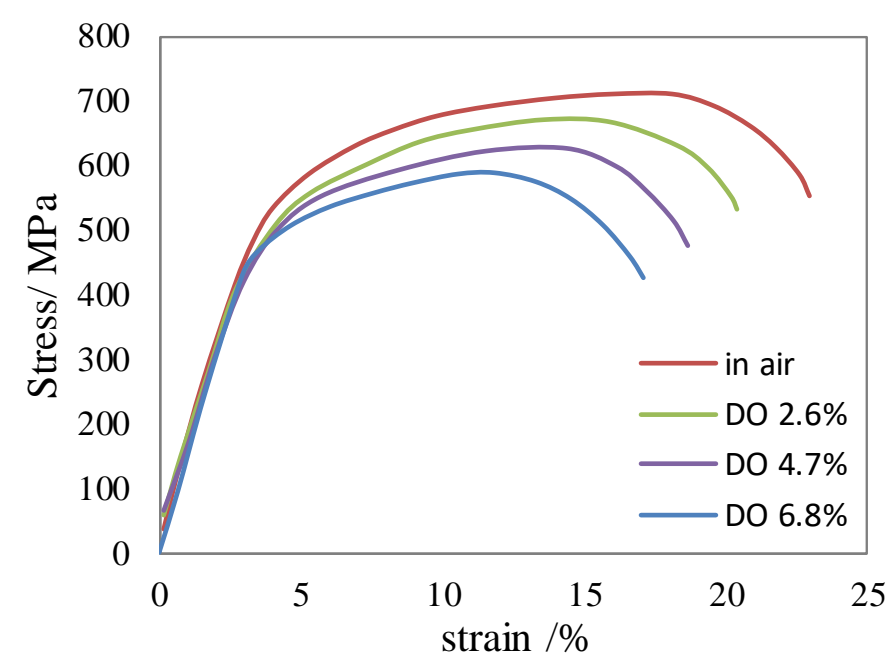

Figure 3: Stress-strain curves of the X80 samples measured in the SSRT tests.

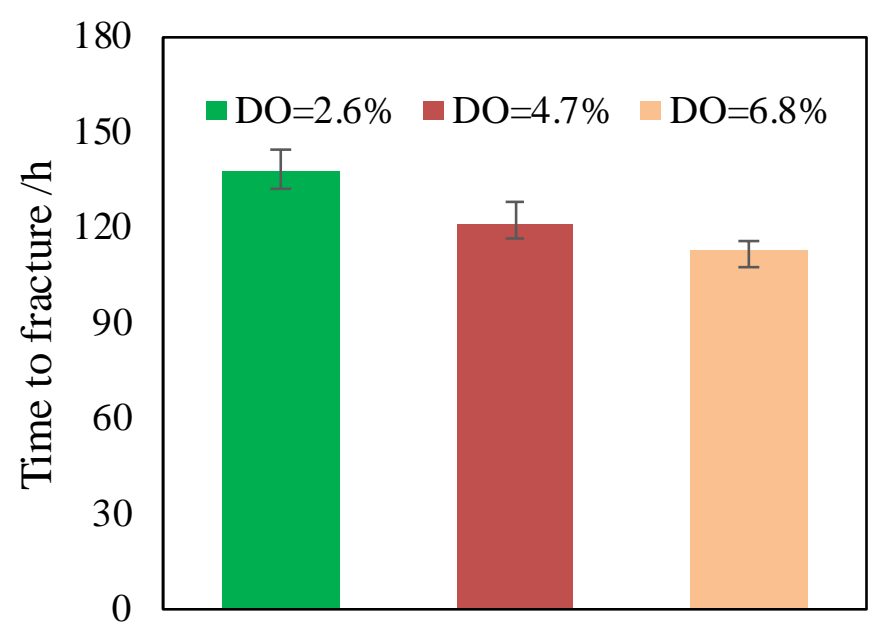

Figure 4: Times to fracture of X80 samples in the seawater with different DO contents.

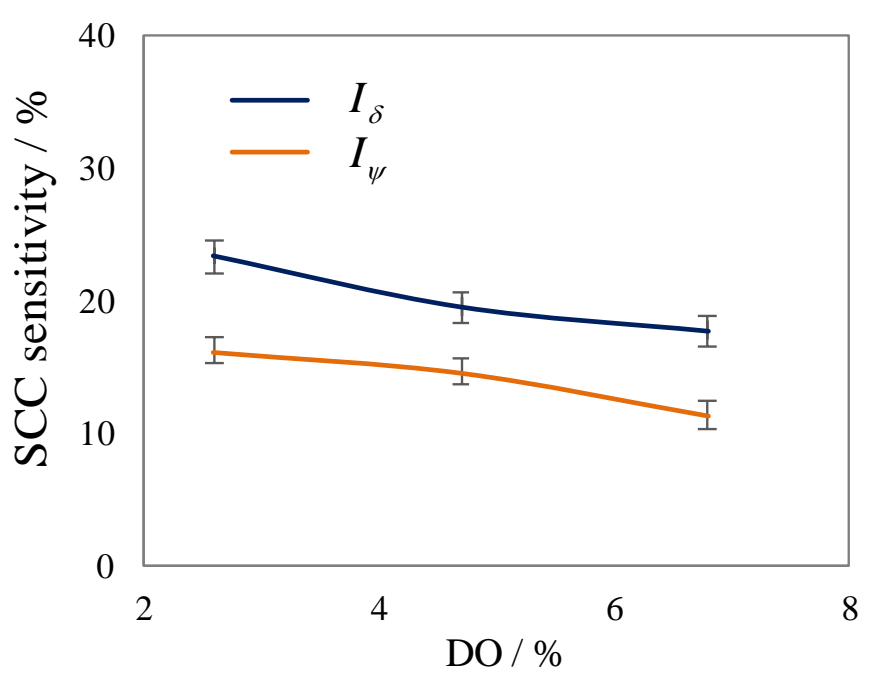

Figure 5: SCC sensitivities (elongation-loss rate $I_{\delta}$, and reduction-in-area loss rate $I_{\psi}$ ) of the X80 samples in the seawater with different DO contents

Fig. 7 shows the morphology evolution at the lateral surface of the samples in the seawater with $6.8 \%$ and $2.6 \%$ DO during the SSRT process. It can be seen that the microcracks gradually nucleates on the lateral surface of the sample with the testing time. In the $2.6 \%$ DO environment, the visible corrosion pits and microcracks begin to emerge after $75 \mathrm{~h}$, but at this moment, the lateral surface is covered with dense corrosion pits and microcracks in the $6.8 \% \mathrm{DO}$ environment. Then micro cracks gradually merge and expand, eventually lead to the fracture of the samples. Comparing these two sets of images, the microcrack distributions at the lateral surface in the $6.8 \% \mathrm{DO}$ seawater are more serious than that in $2.6 \% \mathrm{DO}$ environment, indicating that the dissolved oxygen accelerates corrosion and induces the nucleation of micro crack. The observations are consistent with the results of the RRST tests, and the dissolved oxygen increases the sensitivity of stress corrosion and shortens the stress corrosion life of X80 steel in the natural seawater. 

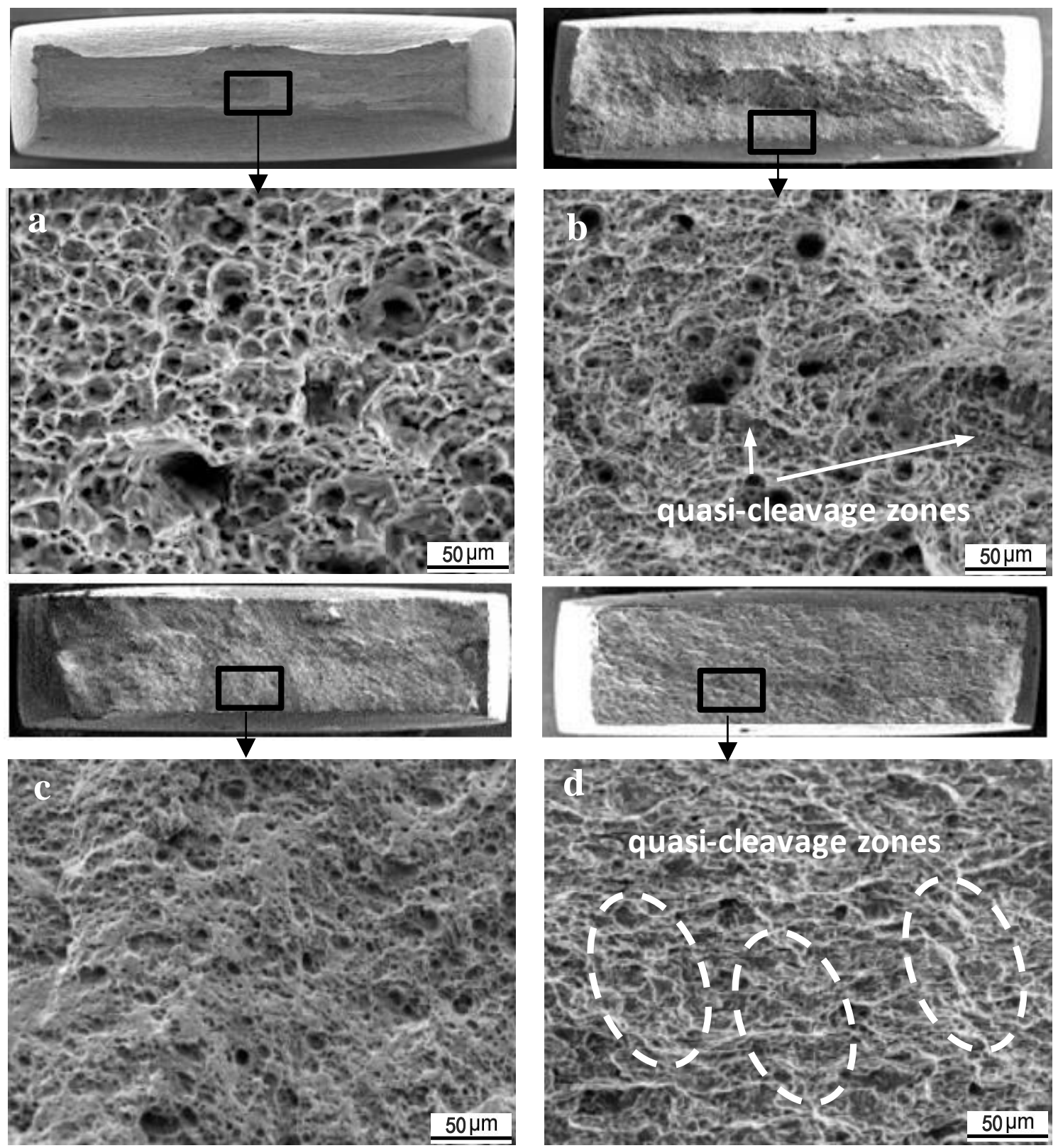

Figure 6: SEM images of the fracture surfaces of X80 steels in (a) in air, (b) $2.6 \% \mathrm{DO}$, (c) $4.7 \%$ DO, (d) $6.8 \%$ DO

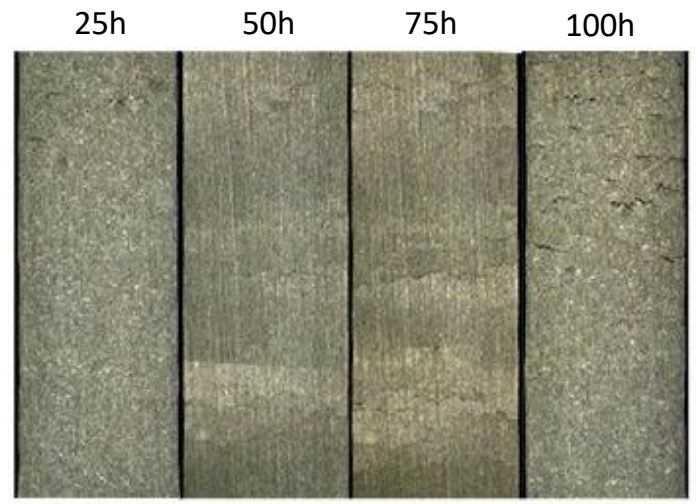

$\mathrm{DO}=2.6 \%$

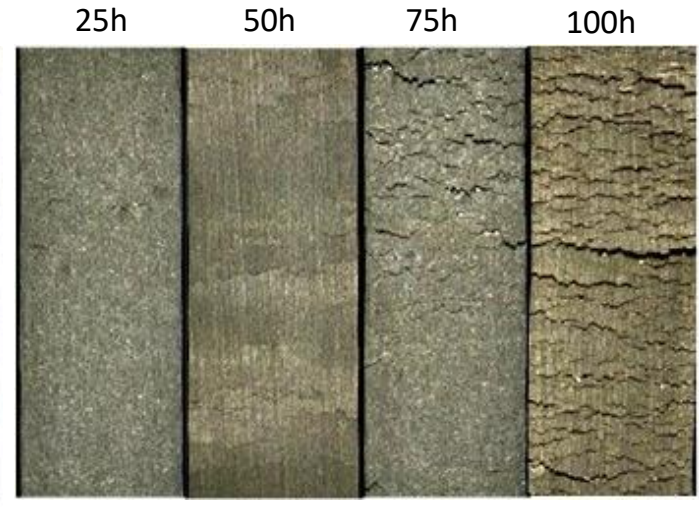

$\mathrm{DO}=6.8 \%$

Figure 7: Variation of the lateral morphology of the samples with testing time 


\section{Discussion}

\section{Effect of DO on electrochemistry corrosion}

o investigate the mechanism that the DO content accelerates the SCC of X80 steel in the natural seawater, the method of electrochemistry measurement was adopted to study the corrosion behavior in the seawater with different DO content. The potentiodynamic polarization measurements were performed in Perkin-Elmer M283 constant potential electrochemical testing system. Polarization measurements were conducted starting from $-250 \mathrm{mV}$ (vs open circuit potential), and scanned toward more positive direction with scanning rate of $0.5 \mathrm{mV} / \mathrm{s}$. Electrochemical impedance spectroscopy (EIS) measurements were carried out with a sinusoidal perturbation of $10 \mathrm{mV}$ amplitude at measurement frequency ranging from $100 \mathrm{kHz}-100 \mathrm{mHz}$, aided by M1025 frequency response instrument.

Fig. 8(a) depicts the results of Tafle polarization and EIS Nyquist circuits of X80 steel in the seawater with different DO, and the fitting results of Tafle polarization curves are listed in Tab. 1. It can be seen that (i) the cathodic depolarization reaction gradually transforms from the oxygen reduction reaction to the hydrogen evolution reaction; (ii) the cathodic reaction is suppressed, the cathodic Tafel slope $b_{c}$ decreases and the anodic Tafel slope $b_{\mathrm{a}}$ increases; and (iii) the corrosion current density $i_{\text {corr }}$ decreases from $21.364 \times 10^{-6} \mathrm{~A} / \mathrm{cm}^{2}$ to $4.678 \times 10^{-6} \mathrm{~A} / \mathrm{cm}^{2}$, with the decrease of DO. Fig. 8(b) shows the electrochemical impedance spectroscopy of X80 steel under different DO contents. It can be seen that in the low DO environment, the capacitive reactance arc of X80 steel is larger than that under high DO environment, indicating that the decrease of DO resulting in an increase of corrosion resistance. At the same time, the higher resistance of the reaction decreases the corrosion rate, which is consistent with the results obtained by the polarization curve.
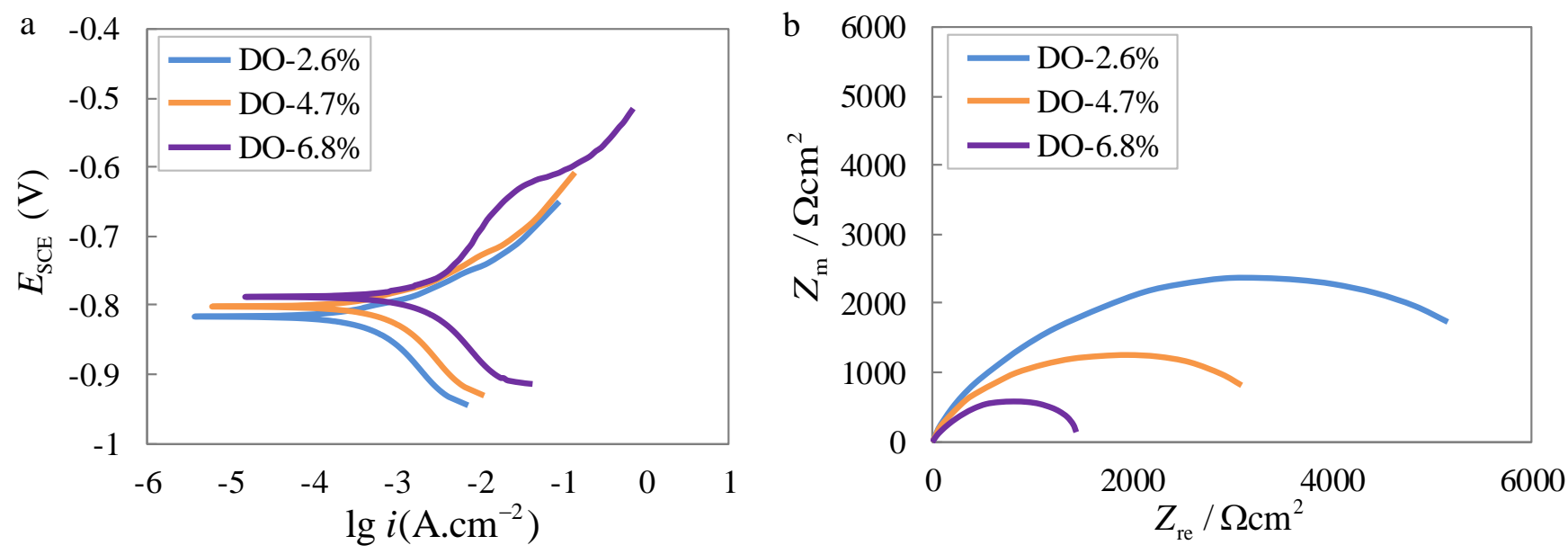

Figure 8: Results of electrochemical measurements: (a) Tafle polarization curves; (b) Nyquist plots.

\begin{tabular}{c|cccc}
\hline $\mathrm{DO}(\%)$ & $E_{\text {corr }}(\mathrm{V})$ & $i_{\text {corr }}\left(\mu \mathrm{A} \cdot \mathrm{cm}^{2}\right)$ & $b_{\mathrm{a}}\left(\mathrm{V} \cdot \mathrm{dec}^{-1}\right)$ & $b_{\mathrm{c}}\left(\mathrm{V} \cdot \mathrm{dec}^{-1}\right)$ \\
2.6 & -0.883 & 4.678 & 0.093 & 0.038 \\
4.7 & -0.866 & 9.332 & 0.087 & 0.097 \\
6.8 & -0.856 & 21.364 & 0.072 & 0.153 \\
\hline
\end{tabular}

Table 1: The instantaneous electrochemical parameters from polarization curve.

\section{Stress concentration promotes SCC fracture}

The stress corrosion mechanism of X80 steel in the seawater is widely recognized as the combined effect of corrosion pits or hydrogen-induced cracking [16-17]. Therefore, the formation of corrosion pit during stress corrosion process is strongly influenced by the tensile stress [18-19]. From Fig. 6, there are numerous corrosion pits and micro cracks at the lateral surface of the tested sample, and these defects, especially microcracks can cause a serious stress concentration, as shown in Fig. 9. Corresponding to the principle of thermodynamics and electrochemical theory, the anodic dissolution current density $i_{\mathrm{p}}$ under an active dissolution condition, such as corrosion pit and microcrack, can be expressed as [16, 20] 


$$
i_{\mathrm{p}}=i_{0} \exp \left(\frac{\Delta G}{R T}\right)=i_{0} \exp \left(\frac{M\left(m \sigma^{m+1}+\sigma_{s}^{m+1}\right)}{(1+m) p^{m} \rho \mathrm{RT}}\right)=k_{\mathrm{p}} i_{0}
$$

where $\Delta G$ is the change of Gibbs free energy, $R$ is universal gas constant, $T$ is absolute temperature value, $i_{0}$ is anodic dissolution current density in the condition of no applied stress, $M$ and $\varrho$ are the molar mass and the density of the electrode material, $p$ and $m$ are the material constants using the Ramberg-Osgood power model, $\sigma_{\mathrm{s}}$ is the yielding strength of the electrode material, and $k_{\mathrm{p}}$ is the current concentration factor.
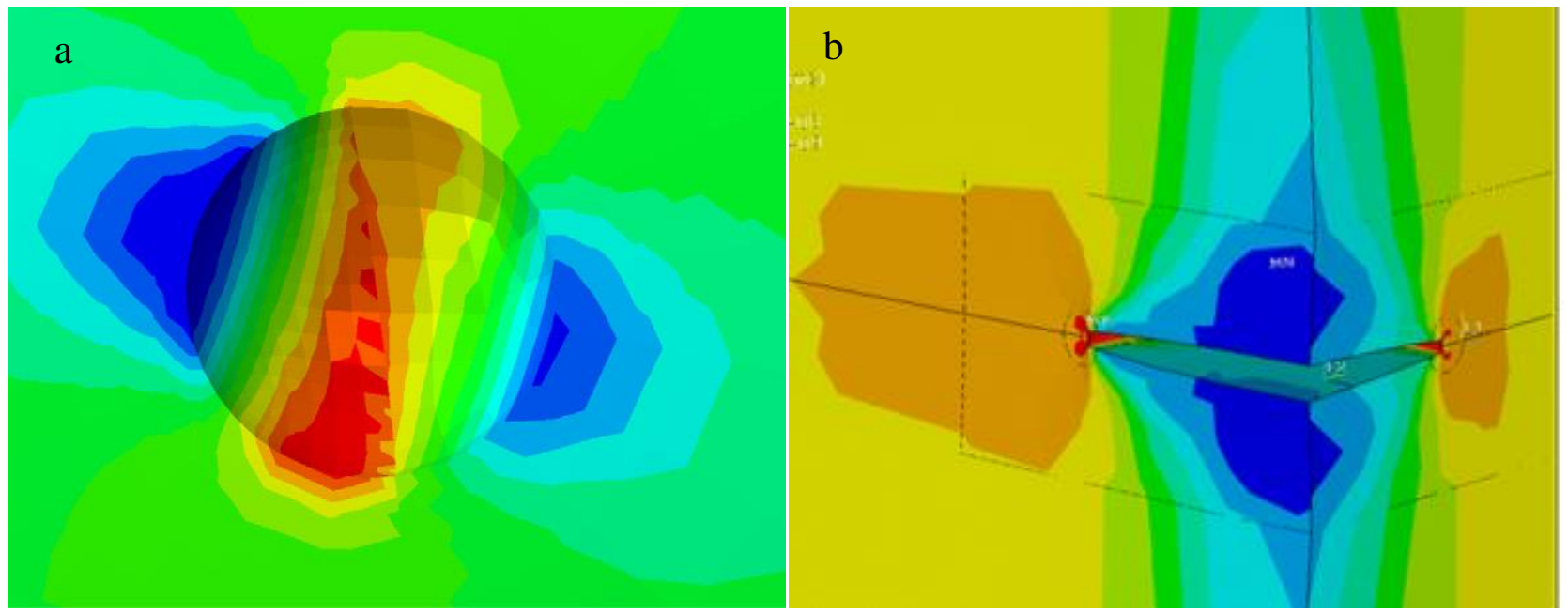

Figure 9: Stress concentration at the corrosion pit and microcrack: (a) corrosion pit, (b) microcrack.

From Fig. 9, the stresses at the bottom of the corrosion pit and the tip of crack are far bigger than the applied tensile stress. According to Eqn. (3), the anodic dissolution current density $i_{\mathrm{p}}$ increases drastically, which significantly promote the anodic dissolution of the metal at the pits and microcracks, resulting in the accelerating loss in cross-sectional area and fracture process of the sample. Fig. 10 depicts the variation of current concentration factor $k_{\mathrm{p}}$ with the concentrated stress, and the measured current densities of X80 steel from Ref. [19] are quoted and were depicted in Fig. 10 for comparison. Although the current concentration factors of the measured currents under different stresses have certain differences with the theoretical $k_{\mathrm{p}}$, the fact that high stress increases the anode dissolution current can be affirmative.

From the above analysis, it can be seen that even under lower applied stress, the stress concentration can cause local high stress at the corrosion pit and crack tip. The interaction of high stress and electrochemical reaction promotes the anodic dissolution and the growth of corrosion pits and cracks, thereby accelerates the process of stress corrosion cracking of the X80 steel in the seawater.

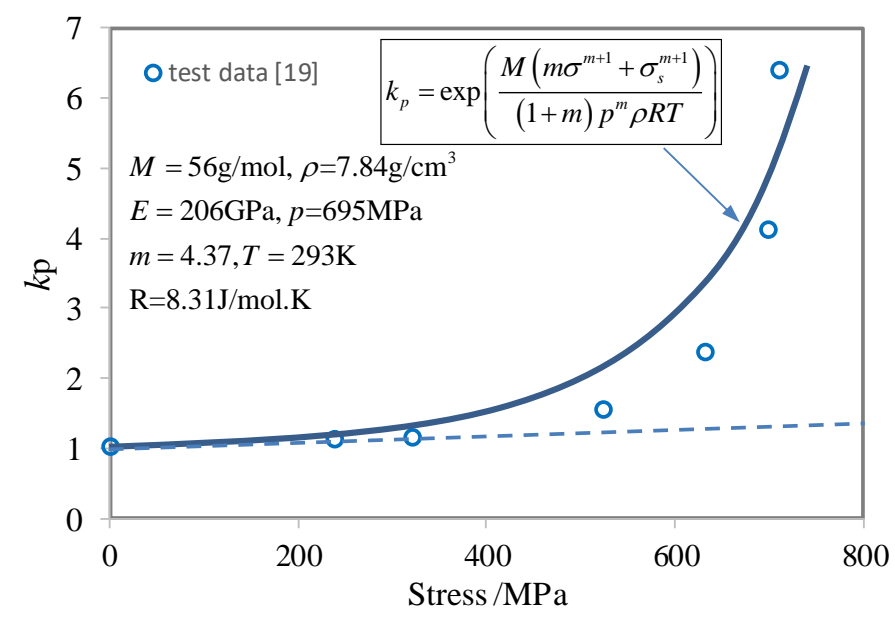

Figure 10: The effect of applied stress on active anodic dissolution 


\section{CONCLUSION}

I $\mathrm{n}$ the present study, the stress corrosion SSRT tests of X80 steel in the natural seawater with different DO contents were conducted to analyze the stress corrosion sensitivity. SEM and the electrochemical measurements are adopted to investigate the stress corrosion mechanism and the contribution of DO on the SCC behavior. The main results obtained can be concluded as follows:

(1) X80 steel has a strong susceptibility of SCC to the DO content in the natural seawater. The stress corrosion lives decrease with the increase of DO, i.e., the stress corrosion of X80 steel is more serious in the shallow sea. The decrease in elongation-loss rate and reduction-in-area loss rate indicate the susceptibility of SCC increasing with the increase of DO.

(2) The distribution of the corrosion pits and micro cracks at the lateral and fracture surfaces aggravate with the increase of DO, which is consistent with the time-to fracture results of SSRT tests. The fracture of X80 steel possesses some quasi-cleavage zones in low DO, but the number of ductile dimples decreases and the size of ductile dimple also shrinks when DO content increases to $6.8 \%$, revealing that the fracture transforms gradually from ductile fracture to quasibrittle fracture.

(3) The results of Tafle polarization and electrochemical impedance spectroscopy show that the corrosion current increase and corrosion resistance decrease at higher DO, indicating that the increase of DO content results in a speeded-up of corrosion. At the same time, corrosion pits and micro cracks at the lateral surfaces cause the stress concentration and promote the anodic dissolution and growth of corrosion pits and cracks even under lower applied stress, thereby accelerates the process of stress corrosion cracking of X80 steel in the seawater.

\section{ACKNOWLEDGMENTS}

he research work is supported by the National Natural Science Foundation of China (No.51404286), and the Fundamental Research Funds for the Central Universities of China (No.17CX02065). The authors are also grateful for the financial support from China Scholarship Council (No. 201806455016).

\section{REFERENCES}

[1] Caleyo, F., González, J.L., Hallen, J.M. (2002). A study on the reliability assessment methodology for pipelines with active corrosion defects. International Journal of Pressure Vessels and Piping, 79(1), pp. 77-86.

DOI: 10.1016/S0308-0161(01)00124-7.

[2] Lai, Z.S., Chen, Q.S., Wang, C.F., Zhou, X.L. (2019) Modeling dynamic responses of heterogeneous seabed with embedded pipeline through multiresolution random field and coupled hydromechanical simulations. Ocean Engineering, 173, pp. 556-570. DOI: 10.1016/j.oceaneng.2019.01.015.

[3] Eliassen, S. (2004). New concept for cathodic protection of offshore pipelines to reduce hydrogen induced stress cracking (HISC) in high strength 13\%Cr stainless steels. Corrosion Engineering, Science and Technology, 39(1), pp. 31-37. DOI: $10.1179 / 147842204225016868$.

[4] Chen, Y.F., Zhang, H., Zhang, J., Liu, X.B., Li, X., Zhou, J. (2015). Failure assessment of X80 pipeline with interacting corrosion defects. Engineering Failure Analysis, 47, pp. 67-76. DOI: 10.1016/j.engfailanal.2014.09.013.

[5] Li, X.H., Chen, G.M., Chang, Y.J., Xu, C.H. (2019). Risk-based operation safety analysis during maintenance activities of subsea pipelines. Process Safety and Environmental Protection, 122, pp. 247-262. DOI:10.1016/j.psep.2018.12.006.

[6] Yang, Y.S., Khan, F., Thodi, P., Abbassi, R. (2017) Corrosion induced failure analysis of subsea pipelines. Reliability Engineering \& System Safety, 159, pp. 214-222. DOI: 10.1016/j.ress.2016.11.014.

[7] Arafin, M.A., Szpunar, J.A. (2009). A new under- standing of intergranular stress corrosion cracking resistance of pipeline steel through grain boundary character and crystallographic texture studies. Corrosion Science, 51(1), pp.19128. DOI: $10.1016 /$ j.corsci.2008.10.006.

[8] Charles, E.A., Parkins, R.N. (2015). Generation of stress corrosion cracking environments at pipeline surfaces. Corrosion, 51(7), pp. 518-527. DOI: 10.5006/1.3294372. 
[9] Arafin, M.A., Szpunar, J.A. (2009). A new understanding of intergranular stress corrosion cracking resistance of pipeline steel through grain boundary character and crystallographic texture studies. Corrosion Science, 51(1), pp. 119-128. DOI: $10.1016 /$ j.corsci.2008.10.006.

[10]Liu, Z.Y., Li, X.G., Cheng, Y.F. (2012). Mechanistic aspect of near-neutral pH stress corrosion cracking of pipelines under cathodic polarization. Corrosion Science, 55, pp. 54-60. DOI: 10.1016/j.corsci.2011.10.002.

[11] Sun, F.L., Ren, S., Li Z., Liu Z.Y., Li X.G., Du C.W. (2017).Comparative study on the stress corrosion cracking of X70 pipeline steel in simulated shallow and deep sea environments. Materials Science \& Engineering A, 685, pp.145-153. DOI: $10.1016 /$ j.msea.2016.12.118.

[12]Liu, Y., Wang, J.W., Liu, L., Li, Y., Wang, F.H. (2013). Study of the failure mechanism of an epoxy coating system under high hydrostatic pressure. Corrosion Science, 74, pp. 59-70. DOI: 10.1016/j.corsci.2013.04.012.

[13] Melchers, R.E. (2015). Effect of immersion depth on marine corrosion of mild steel. Corrosion, 61, pp. 895-906. DOI: $10.5006 / 1.3280659$.

[14]Junghans, A., Chellappa, R., Wang, P., Majewski, J., Luciano, G., Marcelli, R., Proietti, E. (2015). Neutron reflectometry studies of aluminum-saline water interface under hydrostatic pressure. Corrosion Science, 90, pp.101-106. DOI: 10.1016/j.corsci.2014.10.001.

[15]Zhang, T., Yang, Y.G., Shao, Y.W., Meng, G.Z., Wang, F.H. (2009). A stochastic analysis of the effect of hydrostatic pressure on the pit corrosion of Fe-20Cr alloy. Electrochimica Acta, 54, pp. 3915-3922.

DOI: 10.1016/j.electacta. 2009.02.010.

[16] Huang, Y.H., Xuan, F.Z., Tu, S.T. Itoh, T. (2011). Effects of hydrogen and surface dislocation on active dissolution of deformed 304 austenitic stainless steel in acid chloride solution. Materials Science and Engineering A, 528, pp.18821888. DOI: $10.1016 /$ j.msea.2010.10.055.

[17]Huang, Y.H., Tu, S.T., Xuan, F.Z. (2013). Modeling and simulation of pit chemistry of 304 austenitic stainless steel under applied stress in sodium chloride solution. Nuclear Engineering and Design, 257, pp.45-52.

DOI: 10.1016 /j.nucengdes. 2013.01.019.

[18] Mao, S.X., Li, M. (1998) Mechanics and thermodynamics on the stress and hydrogen interaction in crack tip stress corrosion: experiment and theory. Journal of the Mechanics and Physics of Solids, 46(6), pp. 1125-1137.

DOI: 10.1016 /S0022-5096(97)00054-9.

[19] Wang, Y.X., Zhao, W.M., Ai, H., Zhou, X.G., Zhang, T.M. (2011). Effects of strain on the corrosion behaviour of X80 steel. Corrosion Science, 53, pp.2761-2766. DOI: 10.1016/j.corsci.2011.05.011.

[20] Ramberg, W., Osgood, W.R. (1943). Description of stress-strain curves by three parameters. NACA Technical Note No. 902. 